\title{
A CONCRETIZAÇÃO DO ESTADO DE DIREITO AMBIENTAL SEGUNDO A PROPOSTA DA UNIÃO INTERNACIONAL PARA CONSERVAÇÃO DA NATUREZA: LIMITES E POSSIBILIDADES
}

\author{
THE CONCRETIZATION OF THE STATE OF \\ ENVIRONMENTAL LAW ACCORDING TO THE \\ PROPOSAL OF THE INTERNATIONAL UNION FOR \\ THE CONSERVATION OF NATURE: LIMITS AND \\ POSSIBILITIES
}

\author{
Reginaldo PEREIRA" \\ MAURÍCIO BERGER"*
}

\section{RESUMO}

O objetivo do presente artigo é analisar os limites para a concretização do Estado de Direito Ambiental, conforme proposta formulada no Primeiro Congresso Mundial de Direito Ambiental promovido pela União Internacional para Conservação da Natureza (IUCN) e entidades ligadas ao Poder Judiciário Brasileiro, em abril de 2016. $\mathrm{O}$ artigo se justifica em razão da necessidade de problematizar acerca das possibilidades da implantação de um modelo de Estado que preze pela garantida da qualidade ambiental, diante dos paradoxos e contradições ligadas à

\section{ABSTRACT}

The objective of this article is to analyze the limits for the implementation of the State of Environmental Law, as proposed in the First World Congress of Environmental Law promoted by the International Union for Conservation of Nature (IUCN) and entities related to the Brazilian Judiciary in April 2016, in the face of the paradoxes and contradictions associated with the affirmation of a fundamental right to the environment and the challenges imposed by the loss of centrality that the processes of globalization impose on the State's normative power.

* Professor do Programa de Pós-Graduação em Direito da Universidade Comunitária da Região de Chapecó (UNOCHAPECÓ). Doutor em Direito pela Universidade Federal de Santa Catarina (UFSC). Coordenador do Grupo de Pesquisa Direito, Democracia e Participação Cidadã da Universidade Comunitária da Região de Chapecó (UNOCHAPECÓ). Email: rpereira@unochapeco.edu.br

* Professor do Programa de Doctorado en Administración y Política Pública - CONICET IIFAP da Universidad Nacional de Córdoba UNC. Doutor em Sociologia pela Universidad de Buenos Aires. Bolsista de pós-doutorado - Consejo Nacional de Investigaciones Científicas y Técnicas (CONICET/ IIFAP FCS UNC).

Email: mauricio.berger@gmail.com 
afirmação de um direito fundamental ao meio ambiente e dos desafios impostos pela perda de centralidade que os processos de globalização impõem ao poder normativo do Estado. Para tanto, estabelecem-se, inicialmente, as diferenças entre as propostas de Estado de Direito e de Estado de Direito Ambiental, com ênfase nas funções comunicacionais dessa nova proposta e, em seguida se problematiza acerca de dois fatores endógenos ligados à proposição da IUCN: a natureza jurídica do direito fundamental ao meio ambiente e as dificuldades que representa para que possa esverdear o Estado de Direito, transformando-o em Estado de Direito Ambiental e um fator externo: o cenário geopolítico no qual se pretende construir o novo modelo de Estado. A pesquisa que deu origem ao presente trabalho é teórica, mediante consulta a fontes bibliográficas em diversos meios e o método adotado é o dedutivo. Conclui-se que o Estado de Direito Ambiental é um devir e que seu sucesso dependerá do alargamento da noção de direito ao meio ambiente, que necessariamente terá que considerar aspectos não humanos e da capacidade comunicacional do Estado em um contexto policêntrico imposto pela globalização econômica.

PALAVRAS-CHAVE: Estado de Direito Ambiental. Direito ao Meio Ambiente. Globalização Econômica. Poder Normativo do Estado.
Therefore, in first place the differences between the proposals of the State of Law and the State of Environmental Law are established, with an emphasis on the communicational functions of this new proposal, and then it is problematized about two endogenous factors linked to the IUCN proposal: the legal nature of the fundamental right to the environment and the difficulties it faces in order to turn the rule of law greener, transforming it into a state of environmental law and an external factor: the geopolitical scenario in which the new state model is to be constructed. The research that gave origin to the present work is theoretical, through consultation to bibliographic sources in several means and the adopted method is the deductive one. It is concluded that the Environmental Rule of Law is a becoming and that its success will depend on the extension of the notion of right to the environment, which will necessarily have to consider non-human aspects and the state's communication capacity in a polycentric context imposed by economic globalization.

KEYWORDS: State of Environmental Law. Right to the Environment. Economic Globalization. Normative Power of the State.

\section{INTRODUÇÃO}

De 27 a 29 de abril de 2016, aconteceu na cidade do Rio de Janeiro, o Primeiro Congresso Mundial de Direito Ambiental, promovido por entidades ligadas ao judiciário brasileiro e pela IUCN (União Internacional para Conservação da Natureza).

O objetivo deste Congresso foi debater e construir as bases jurídicas de um novo modelo de Estado.

Com fundamento legal na justiça ambiental e com base na responsabilidade ecológica, social e cultural para alcançar um futuro saudável, pacífico, inclusivo e sustentável, o Estado de Direito Ambiental procura estender à esfera ambiental os princípios e proteções processuais e substanciais consagrados no Estado de Direito, aliados a instituições fortes para o desenvolvimento, 
implementação e cumprimento de leis, regulamentos e políticas nos níveis nacional, subnacional, regional e internacional .

No Congresso foi redigida a Declaração Mundial sobre o Estado de Direito Ambiental (World Declaration on the Environmental Rule of Law).

A Declaração enumera 11 Princípios Fundamentais Gerais e Emergentes para Promover e Alcançar a Justiça Ambiental por meio do Direito Ambiental.

O princípio um impõe a todas as pessoas, Estados e entidades privadas a responsabilidade universal de cuidar e promover o bemestar de outras espécies e ecossistemas, independentemente do seu valor para os seres humanos, e de seu uso e exploração. Toda vida tem o direito inerente de existir.

O segundo princípio da Declaração confere a todas as pessoas o direito à natureza como herança comum da humanidade, pois: "[...] a experimentação da natureza é vital para a saúde mental e física dos seres humanos e serve como catalisador para a apreciação da importância de ser protegida a base ambiental da qual depende a vida e o bem-estar humano."

A expressão "in dubio pro natura" traduz o conteúdo do terceiro princípio. Por força dele, em caso de dúvida, as questões devem ser resolvidas de forma a favorecer a proteção e a Conservação do meio ambiente, dando preferência a alternativas que sejam menos nocivas para o ambiente. O princípio impede, ainda, a execução de empreendimentos e ações humanas que apresentem potenciais impactos à qualidade ambiental desproporcionais aos benefícios sociais delas decorrentes.

O princípio quatro determina a adoção de medidas legais e administrativas visando proteger e restaurar a integridade dos ecossistemas e reforçar a resiliência dos sistemas sócio-ecológicos. $\mathrm{Na}$ elaboração de legislação e de políticas públicas, a manutenção de uma biosfera saudável deve ser uma variável primordial.

O quinto princípio preconiza, por um lado, o acesso justo e equitativo aos benefícios dos serviços ecossistêmicos e compartilhamento dos mesmos entre as pessoas das atuais gerações e, por outro, a repartição justa e equitativa dos encargos e externalidades da degradação ambiental. O princípio prevê que os 
recursos naturais sejam geridos a partir de critérios que garantam a sua utilização de forma mais econômica possível e a evitação de resíduos.

Se o princípio cinco é dedicado à equidade intrageracional, o sexto trata da equidade intergeracional. A presente geração deve assegurar que a saúde, a diversidade e a produtividade do meio ambiente seja mantida ou restaurada para garantir acesso equitativo aos benefícios do ambiente às gerações vindouras.

A equidade de gênero deve ser incorporada em todas as políticas, decisões e práticas do Estado de Direito Ambiental, determina o princípio de número sete.

O princípio oito garante a participação de grupos minoritários e vulneráveis, no que diz respeito ao acesso à informação e a tomadas de decisão.

$\mathrm{Na}$ mesma linha, o nono princípio assegura o respeito à cultura e à relação com a terra aos indígenas e comunidades tradicionais, garantindo-lhes, ainda, o direito à consulta e ao consentimento livre e prévio.

O princípio dez proíbe a regressão e a diminuição da proteção jurídica do meio ambiente e assegura o acesso à justiça ambiental.

E décimo primeiro princípio, por fim, impõe o dever aos Estados de rever e melhorar as leis e políticas públicas relacionadas com a conservação e proteção do meio ambiente, com base nos conhecimentos científicos mais recentes e na evolução das políticas.

Muito embora a nítida correlação que cada um dos onze princípios mantém com os demais, interessa, para o presente trabalho, precisar o conteúdo jurídico do segundo princípio da declaração, que confere a todas as pessoas o direito à natureza ou ao meio ambiente saudável.

Tal princípio não é novidade. No âmbito do direito internacional público, ele acresce a outros princípios inseridos em declarações que tratam do meio ambiente, tais como o Princípio 1 da Declaração de Estocolmo de 1972 e o Princípio 1 da Declaração do Rio de Janeiro de 1992 Sobre Meio Ambiente e Desenvolvimento que, desde o início da década de 1970, já reconhecem à humanidade o direito a uma vida saudável a ser usufruído em um ambiente ecologicamente equilibrado. 
Da mesma forma, diversas constituições aprovadas ou reformadas depois da Conferência de Estocolmo de 1972 incorporaram tal direito aos seus textos, elevando-o a status de direito fundamental.

Se não há dúvidas quanto ao reconhecimento do direito fundamental ao meio ambiente ecologicamente equilibrado, quer por diversos ordenamentos jurídicos ou, mesmo, no plano internacional, o mesmo não pode se afirmar acerca da factibilidade de tal direito e do sucesso do modelo de Estado que pretende sustentar.

Diversos fatores podem ser apontados como empecilhos ou desafios a serem superados para a concretização tanto do direito fundamental ao meio ambiente como da implantação do Estado de Direito Ambiental.

Este trabalho visa problematizar acerca de dois fatores endógenos: a natureza jurídica do direito fundamental ao meio ambiente e as dificuldades que representa para que possa esverdear o Estado de Direito, transformando-o em Estado de Direito Ambiental e um fator externo: o cenário geopolítico no qual se pretende construir o Estado de Direito Ambiental.

Adverte-se, desde já, que não se pretende, neste trabalho, lançar qualquer juízo valorativo sobre a proposta do Estado de Direito Ambiental que venha a lhe desqualificar. Pelo contrário, parte-se do pressuposto da necessidade, acima de tudo, da implantação e consolidação deste modelo de Estado. Todavia, é necessário problematizar e clarear sobre alguns dos desafios a serem superados para que este devir, o Estado de Direito Ambiental, possa se concretizar.

Elegem-se, para tal tarefa, dois desafios à implementação do Estado de Direito Ambiental um de caráter endógeno à proposta e outro externo, em torno dos quais se estrutura o artigo.

Em um primeiro momento, o trabalho trata da natureza jurídica do direito fundamental ao meio ambiente equilibrado e procura problematizar sobre os paradoxos decorrentes da necessidade de se garantir um direito que não pode ser apropriado e que comporta um grau de dever - de caráter fundamental - ligado à manutenção das bases de sustentação das futuras gerações.

O diacronismo do direito ao meio ambiente impõe ao Estado a dura tarefa de equacionar o desfrute de todas as dimensões dos 
direitos fundamentais com as limitações impostas em nome da solidariedade intergeracional.

A segunda parte do artigo é dedicada à perda da centralidade e do poder normativo do Estado diante da emergência de novos atores não estatais e estatais em um cenário de globalização econômica. Parece necessária ou, pelo menos razoável, verificar a possibilidade de afirmação de um modelo de Estado em um contexto marcado pela dificuldade de sua afirmação.

A pesquisa que deu origem ao presente trabalho é teórica, mediante consulta a fontes bibliográficas em diversos meios tais como periódicos científicos, livros, anais de evento, entre outros. O método adotado é o dedutivo.

\section{DESAFIOS PARA A CONCRETIZAÇÃO DA PROPOSTA DO ESTADO DE DIREITO AMBIENTAL}

A International Union for Conservation of Nature define o Estado de Direito Ambiental como a aplicação do estado de direito a nível local, nacional, regional e internacional no contexto ambiental. ${ }^{1}$

O Estado de Direito Ambiental se baseia em elementoschave de governança, incluindo, mas não se limitando a: i) desenvolver, promulgar e implementar leis, regulamentos e políticas claras, rigorosas, executáveis e eficazes que sejam administradas eficientemente por meio de processos justos e inclusivos para alcançar os mais altos padrões de qualidade ambiental a nível nacional, subnacional, regional e internacional; ii) assegurar o cumprimento efetivo das leis, regulamentos e políticas, e a efetivação de medidas adequadas de execução criminal, civil e administrativa e, ainda, de mecanismos de composição, adequados e imparciais, para a resolução de questões relacionadas ao meio ambiente e à sociobiodiversidade; iii) possibilitar o acesso à informação, a participação do público na tomada de decisões e o acesso à justiça e; iv) implementar auditorias e relatórios ambientais, juntamente

1 IUCN, 2016. 
com outros mecanismos eficazes de responsabilização, integridade e anticorrupção. ${ }^{2}$

Nos termos da definição acima, seria uma derivação do Estado de Direito, comprometido em solucionar a questão ambiental.

O Estado de Direito é um modelo pautado, por um lado, na garantia dos direitos fundamentais e, por outro, na centralidade que atribui ao direito, como prática decisória e autolimitadora, principalmente dos poderes estatais.

Já o Estado de Direito Ambiental se constitui em um quadro de mais sociedade, mais direitos e deveres individuais e mais direitos e deveres coletivos e menos Estado e menos mercantilização. Neste novo contexto, não é prioritário o doseamento entre público e privado, mas sim o reforço da autonomia individual e social frente à mercantilização e à burocratização.

O contexto social no qual emerge a proposta de Estado de Direito Ambiental corresponde ao experimentado, nas sociedades centrais, a partir da segunda metade do Século XX e está relacionado ao surgimento de sociedades mais complexas e reflexivas.

A complexidade e a reflexibilidade levam a uma reorientação das atividades estatais que passam, necessariamente, a privilegiar também a defesa de direitos considerados novos - ligados às reivindicações das minorias, ao surgimento da massa de consumidores e à degradação das qualidades do meio ambiente seja em virtude do ineditismo de suas naturezas, seja pela exigência de serem garantidos de uma maneira nova, através da construção de um novo modelo de Estado, que consiga manter conexões, fazer-se presente em um mundo global e que privilegie a arte de bem governar a casa, a arte do "[...] estar no mundo [...]". ${ }^{3}$

O Estado de Direito Ambiental ou Estado Ecológico pressupõe um redirecionamento da função do Estado como organização política visando a abordagem de seus limites e invenções para a sua manutenção como Ator Social privilegiado. Segundo Canotilho ${ }^{4}$ o Estado ecológico é aquele que, “[...] além de ser e dever

2 IUCN, 2016.

3 BERTICELLI, 2004, p. 413.

4 Canotilho, 2004, p. 03. 
ser um Estado de direito democrático e social, deve ser também um estado regido por princípios ecológicos; [...]”, ainda: “[...] o Estado ecológico aponta para formas novas de participação política sugestivamente condensadas na expressão democracia sustentada".

Para Leite ${ }^{5}$ o Estado de direito ambiental é um conceito de cunho teórico-abstrato que abarca elementos jurídicos, sociais e políticos na busca de uma situação ambiental favorável à plena satisfação da dignidade humana e harmonia dos ecossistemas. Suas funções essenciais seriam: i) estabelecer formas mais eficazes de gestão dos riscos, distanciando-se da irresponsabilidade organizada. Não se trata de eliminar os riscos, haja vista serem estes intrínsecos ao modelo de sociedade na qual se insere o Estado de Direito Ambiental e sim, geri-los, para que os efeitos secundários não ultrapassem limites de tolerabilidade; ii) judicizar instrumentos de prevenção e precaução, procurando munir o direito ambiental de meios que evitem a ocorrência de danos de que se apresentam em estado de latência; iii) tornar o direito ambiental integrado, tendo em vista o caráter ubíquo apresentado pelo objeto de proteção que não pode mais ser considerado como conjunto de riquezas segregado, mas sim como bem que se encontra ao mesmo tempo em toda a parte; iv) buscar formar cidadãos aptos à gestão popular dos riscos e; v) estabelecer que o objeto a ser tutelado, o meio ambiente é, por si só, propenso a alterações, encontrando-se em contínuo estado de evolução, estando ainda sujeito a influências de novas energias e matérias lhe agregadas pela ação humana, por conta disto, deve ser tratado de forma aberta e flexível. ${ }^{6}$

Michael Kloepfer ${ }^{7}$ adverte que o conceito de Estado de Direito Ambiental precisa ser clareado, pois ele pode ser entendido de diversas formas, tanto em relação à sua abrangência, quanto ao que respeita ao seu propósito.

O conceito de Estado de Direito Ambiental pretende definir primeiramente um "[...] Estado que faz da incolumidade do seu meio ambiente sua tarefa, bem como o critério e a meta procedimental

\footnotetext{
5 LEITE, 2007, p. 153.

6 LEITE, 2007, p. 152.

$7 \quad$ Kloepfer, 2016.
} 
de suas decisões”. Esta definição não encerra, contudo, todo o conteúdo do termo, já que o elemento social há de ser considerado. Nesse sentido, um Estado de Direito Ambiental, no sentido aqui apresentado, poderia também ser “[...] caracterizado por uma proteção do meio ambiente sustentada mais fortemente pelo setor não estatal". 8

As definições sobre o Estado de Direito Ambiental apresentam - é claro, com as variações que lhes são peculiares dois elementos em comum: o primeiro está relacionado ao objetivo principal deste modelo de Estado, a proteção da incolumidade do meio ambiente e o segundo, à centralidade da figura do Estado. Estes elementos ancorarão as análises acerca dos desafios para a concretização do Estado de Direito Ambiental.

\section{DESAFIOS LIGADOS À TAREFA PRECÍPUA DO ESTADO DE DIREITO AMBIENTAL: A NATUREZA JURÍDICA DO DIREITO FUNDAMENTAL AO MEIO AMBIENTE VERSUS A PRESERVAÇÃO DA QUALIDADE AMBIENTAL}

Como visto, o Estado de Direito Ambiental tem como principal tarefa proteger a qualidade do meio ambiente para as atuais e futuras gerações.

Um dos fundamentos de tal desiderato residiria, conforme o segundo princípio da Declaração Mundial sobre o Estado de Direito Ambiental, no direito de todas as pessoas à natureza, considerada herança comum da humanidade. Em outros termos, o direito fundamental ao meio ambiente se apresenta como um dos fundamentos do Estado de Direito Ambiental.

Sob pena de se cair em contradição e principalmente para que se possa verificar a possibilidade de afirmação do Estado de Direito Ambiental, convém identificar os contornos do direito fundamental ao meio ambiente.

As Declarações da ONU de Estocolmo e do Rio de Janeiro e diversas constituições elevaram o meio ambiente à categoria de direito fundamental indisponível, imprescritível e irrenunciável, 
cujos titulares são todos que compõem as presentes gerações, logo, trata-se de bem difuso - no sentido de pertencer a todos e a ninguém, ao mesmo tempo, ou no sentido de ser um bem ou interesse que difere do interesse público e do privado, constituindo um terceiro gênero - sendo que sua compreensão só é possível a partir da constatação de que se trata de um direito ínsito das sociedades que massificam a produção, o consumo, a informação, a publicidade e o risco.

Além de ser um direito de todos, a higidez ambiental deve ser garantida para as futuras gerações, pois, conforme preconiza o princípio 1 da Declaração de Estocolmo Sobre o Ambiente Humano:

O homem tem o direito fundamental à liberdade, à igualdade e ao desfrute de condições de vida adequadas, em um meio ambiente de qualidade tal que lhe permita levar uma vida digna, gozar de bemestar e é portador solene de obrigação de proteger e melhorar o meio ambiente, para as gerações presentes e futuras. A esse respeito, as políticas que promovem ou perpetuam o "apartheid", a segregação racial, a discriminação, a opressão colonial e outras formas de opressão e de dominação estrangeira permanecem condenadas e devem ser eliminadas. ${ }^{9}$

A Declaração do Rio de Janeiro de 1992 Sobre Meio Ambiente e Desenvolvimento estabelece em seu princípio 1 que: "Os seres humanos estão no centro das preocupações com o desenvolvimento sustentável. Têm direito a uma vida saudável e produtiva, em harmonia com a natureza." 10

Percebe-se que os dois princípios das duas maiores conferências ambientais mundiais organizadas pela ONU condicionam o direito à vida, à qualidade do meio no qual ela se dá. A vida humana, em uma dimensão nitidamente antropocêntrica, a partir das Conferências, restou qualificada pelo adjetivo saudável, como bem ensina Machado ${ }^{11}$ : "As Constituições escritas inseriram o 'direito à vida' no cabeçalho dos direitos individuais. No século

\footnotetext{
9 ONU, 1972.

10 ONU, 1992.

11 Machado, 2002, p. 45.
} 
XX deu-se um passo a mais ao se formular o conceito do 'direito à qualidade de vida'”. No mesmo sentido:

$\mathrm{O}$ reconhecimento do direito a um meio ambiente sadio configura-se, na verdade, como extensão do direito à vida, quer sob o enfoque da própria existência física e saúde dos seres humanos, quer quanto ao aspecto da dignidade dessa existência - a qualidade de vida -, que faz com que valha a pena viver. ${ }^{12}$

Bello Filho ${ }^{13}$ considera ser o direito ao ambiente ecologicamente equilibrado um direito fundamental nas dimensões real, teórica e positiva, pois “[...] desde 1988, com a previsão normativa deste direito fundamental por intermédio do art. 225 da CF, não há mais dúvida sobre seu posicionamento enquanto tal $[\ldots]$... E, para que não restem dúvidas:

A fundamentalidade do direito justifica-se, primeiro, em razão da estrutura normativa do tipo constitucional ("Todos têm direito...”); segundo, na medida em que o rol do art. $5^{\circ}$, sede principal de direitos e garantias fundamentais, por força de seu $\mathbb{2} 2^{\circ}$, não é exaustivo (direitos fundamentais há - e muitos - que não estão contidos no art. $5^{\circ}$ ); terceiro, porquanto, sendo uma extensão material (pois salvaguarda suas bases ecológicas vitais) do direito à vida, garantido no art. $5^{\circ}$, caput, reflexamente, recebe deste as bênçãos e aconchego, [...]. ${ }^{14}$

Por ser fundamental é de aplicabilidade imediata, ou seja, independentemente de qualquer regulamentação, vincula o Estado à sua defesa e preservação - dever positivo, representado por verdadeiras obrigações de fazer - e impõe-lhe restrições à atuação como agente empreendedor - dever negativo, representado por obrigações de não fazer.

A pertença à terceira dimensão de direitos, pautada na fraternidade, importa à coletividade a atribuição de defendê-lo e preservá-lo. Benjamin ${ }^{15}$ assim o caracteriza:

12 MILARÉ, 2005, p. 158-159.

13 Bello Filho, 2004, 103.

14 BENJAMIN, 2007, p. 102.

15 Benjamin, 2007, p. 103. 
Trata-se de direito, como atrás visto, com estrutura bifronte, a um só tempo negativa - associado a um non facere - e positiva, isto é, um direito que comanda prestações positivas do Estado e da sociedade. É direito de exercício coletivo (art. 129 , III e $\$ 1^{\circ}$ ), mas também individual, não se perdendo a característica unitária do bem jurídico ambiental cuja titularidade reside na comunidade ("todos") - ao reconhecer-se um direito subjetivo ao meio ambiente ecologicamente equilibrado.

Estreme de dúvidas resta, assim, o meio ambiente como direito fundamental de todos. Uma questão, no entanto, é essencial para o presente trabalho: quem são os destinatários do direito fundamental ao meio ambiente.

A acepção dos destinatários irá se alterar em função da ideologia que informa a sua elaboração intelectual.

Duarte $^{16}$ enumera três posições divergentes em relação à percepção da problemática ambiental na sociedade moderna: i) na primeira, há um total descompromisso com a questão ambiental, nesta estariam incluídos os que por entenderem a irrelevância dos problemas ambientais apregoam que o direito não deveria deles se preocupar; ii) na segunda encontram-se aqueles que percebem a proteção do meio ambiente como parte da tutela dos direitos dos seres humanos; iii) na terceira, situam-se os ecofundamentalistas, ou seja, aqueles que, segundo a autora, amparados em "[...] uma inconsequente, imatura, utópica, e romântica visão da questão ambiental [...]” parecem “[...] ignorar o complexo estágio econômico, social e político em que se encontra a sociedade, em que a proteção e defesa ambiental não pode significar a estagnação das atividades sociais, econômicas e políticas".

$\mathrm{Na}$ mesma linha, ao abordar o papel exercido pelo judiciário na aplicação da justiça ambiental, Milaré ${ }^{17}$, assevera:

$\mathrm{Na}$ tutela jurisdicional do meio ambiente pode o juiz defrontar-se com duas posições geralmente antagônicas, que não atendem à necessidade social de desenvolvimento sustentável. De um lado, a defesa cega de determinados bens ambientais, numa visão reducionista e eivada de insensibilidade ante o imperativo de avanços econômicos e sociais. De outro, as falácias que mascaram a inviabilidade ecológica de

16 Duarte, 2004, p. 515.

17 Milaré, 2005, p. 238. 
empreendimentos, estes sim insensíveis à preservação da qualidade ambiental e dos recursos naturais necessários às presentes e futuras gerações.

As críticas dirigidas às duas posições, consideradas pelo autor extremas, denotam a sua preferência por uma posição intermediária capaz de conciliar desenvolvimento com conservação, ou seja, de garantir o meio em função das necessidades humanas. Não sem razão, que, mais adiante, aconselha: "Precaução primeira é manter-se imune aos gritos das cassandras dos movimentos ambientalistas radicais ou estremados, assim como ao canto de sereia do liberalismo, que, com seu laissez faire, laissez passer, privilegia interesses de indivíduos e grupos em detrimento do interesse maior da coletividade". ${ }^{18}$

Poder-se-ia, então, atrelar a noção dos destinatários a três perspectivas: antropocêntrica clássica, biocêntrica e antropocêntrica alargada.

O antropocentrismo clássico está centrado no homem e é fruto, em um primeiro momento, da história da modernidade, da necessidade de superar-se o teocentrismo então vigente. Com a possibilidade de dominação da natureza através da razão instrumental, o homem "elevou-se" a patamares jamais atingidos.

A visão antropocêntrica clássica restringe os destinatários aos seres humanos.

O biocentrismo é diametralmente oposto ao antropocentrismo clássico. Segundo esta corrente filosófica, todas as formas de vida detêm a mesma importância, não havendo distinção hierárquica entre a humanidade e os demais componentes da ecosfera que passariam de objeto a sujeitos de direito.

O biocentrismo é relacionado por alguns autores ${ }^{19}$ à ecologia profunda (deep ecology) ${ }^{20}$ a qual é alimentada por um

18 MILARÉ, 2005, p. 238.

19 Leite, 2000; Bello Filho, 2004.

20 A ecologia profunda é definida como a “[...] perspectiva segundo a qual os seres humanos são equivalentes às outras espécies integradas no interior de ecossistemas em funcionamento, e não superiores. A cosmovisão resultante é mais ecocêntrica do que antropocêntrica". (ART, 1998, p. 175). 
impulso romântico extraordinário de retorno à natureza. O principal problema da concepção biocêntrica é a supressão que promove do elemento cultural do meio ambiente, pois ao tornar ilimitado o reino do natural, a pretexto, nomeadamente, de uma poderosa mitologização da vida, suprime-se por completo a parte do cultural. ${ }^{21} 22$

Em relação a um de seus efeitos, em especial, o biocentrismo promove, tal qual o antropocentrismo clássico a dicotomia homem/ natureza e, por esta razão, a noção de destinatário poderia ser tomada a partir da exclusão do ser humano.

As limitações apresentadas pelas teorias informadas pelo antropocentrismo e biocentrismo possibilitaram o surgimento de uma terceira corrente.

A partir de uma noção antropocêntrica alargada, os destinatários do direito ao meio ambiente seriam todos os seres humanos, desta e das futuras gerações, e os demais componentes bióticos e abióticos que compõem todos os ecossistemas, tomados de per si e/ou integrados, já que essenciais à sadia qualidade de vida dos seres humanos.

$\mathrm{O}$ antropocentrismo alargado busca se estabelecer entre o antropocentrismo clássico e o biocentrismo, para, desta forma, tratar do meio ambiente a partir de uma perspectiva que viabilize a proteção da sanidade ambiental para a sadia qualidade da vida em todas as suas formas, sejam humanas ou não.

Leite, ${ }^{23}$ um dos mais expressivos articulistas do conceito no Brasil, observa, inicialmente, que o antropocentrismo alargado busca superar o clássico sem, contudo, adentrar nos postulados do biocentrismo e é, na verdade, fruto de uma evolução da visão

21 OST, 1997, p. 13-15.

22 Este posicionamento de OST em relação ao biocentrismo não é unânime. Atribuindo o conceito de ecologia profunda à escola de pensamento fundada pelo filósofo norueguês Arne Naes, no início da década de 1970, Capra (2003, 20-21) entende que ela não separa o homem do ambiente, não percebe o mundo como uma coleção de objetos isolados e sim como uma rede de fenômenos interligados e interdependentes. Nas palavras do autor: "A ecologia profunda reconhece o valor intrínseco de todos os seres vivos e encara o homem como apenas um dos filamentos da teia da vida. Reconhece que estamos todos inseridos nos processos cíclicos da natureza e que deles dependemos para viver".

23 Leite, 2000, p. 72-96. 
antropocêntrica, operacionalizada como resposta às críticas dos biocentristas sobre uma eventual supremacia do homem sobre a natureza.

Para o autor, princípios inseridos no ordenamento jurídico brasileiro a partir da promulgação da Constituição da República Federativa do Brasil, de 1988, como o do desenvolvimento sustentável e o da equidade intergeracional, que também são observados em outras constituições, “[...] exigem restrições das atividades econômicas, considerando as necessidades da preservação do ecossistema e, assim, uma maior 'reverência pela natureza' e distanciamento da visão antropocêntrica radical [...]", ${ }^{24}$ impondo "[...] uma verdadeira solidariedade e comunhão de interesses entre o homem e a natureza, como condição imprescindível para assegurar o futuro de ambos e dependente de forma insofismável da ação do primeiro, como verdadeiro guardião da biosfera". ${ }^{25}$

$\mathrm{O}$ antropocentrismo alargado visa, ainda, superar a noção economicêntrica mediante a qual a preservação dos elementos dos ecossistemas se encontra adstrita ao valor destes como recursos naturais ${ }^{26}$, passíveis de apropriação econômica pelo homem, e que devem ser preservados em função única e exclusiva desta qualidade. "Com efeito, esta proposta visa, de maneira adversa, a abranger também a tutela do meio ambiente, independentemente da sua utilidade direta, e busca a preservação da capacidade funcional do patrimônio natural, com ideais éticos de colaboração e interesse". ${ }^{27}$

A defesa do meio ambiente fundada na necessidade da manutenção do equilíbrio ecológico, como valor que deva ser garantido não somente pela importância cultural e econômica que apresenta, avultou-se com a percepção dos efeitos oriundos da modernização e da globalização econômica sobre grandes

24 LEITE, 2000, p. 78.

25 LEITE; AYALA, 2003, p. 212.

26 Derani (1997, p. 71) enumera os elementos integrativos da noção economicista da natureza: “[...] natureza é recurso (matéria a ser apropriada) natural, e o homem, sujeito apartado do objeto a ser apropriado, não é mais natureza. Sujeito e objeto vivem dois mundos: mundo social e mundo natural. Meio ambiente, seria toda a 'entourage' deste solitário sujeito".

27 LEITE, 2000, p. 79. 
biomas e processos ecológicos de regulação - como, por exemplo, o responsável pela manutenção da temperatura global em níveis adequados.

E, é neste ponto que se pretende inserir a abordagem realizada no presente trabalho.

As constatações acima, além de alargarem o alcance dos destinatários do direito ao meio ambiente impõem, por mais paradoxal que pareça, limites ao exercício de tal direito, já que, a consideração do seu caráter difuso leva inevitavelmente à conclusão de que este só pode ser exercido por toda a coletividade, não mais restrita somente aos seres humanos, ao mesmo tempo.

Em outros termos, o reconhecimento do direito fundamental ao meio ambiente acarreta no reconhecimento da existência de deveres e abstenções, não condizentes com a noção individualista dos direitos humanos, que se constitui em uma das principais características do Estado de Direito, e esbarra no dever inafastável do Estado de Direito Ambiental de preservar e recuperar a qualidade do meio ambiente.

Dessa forma, levando-se em consideração o princípio do direito ao meio ambiente, o Estado de Direito Ambiental: ou não é uma derivação do Estado de Direito ou se constitui em uma reorientação radical dos princípios, objetivos e funções do Estado de Direito.

A assertiva reside na lógica que subjaz às gerações ou dimensões ${ }^{28}$ de direitos que informam cada modelo de Estado de

28 Autores como Marshall (1967, p. 67-114) e Bobbio (1992) classificam os direitos fundamentais conforme vêm sendo incorporados historicamente pelas sociedades, para tanto utilizam a expressão geração de direitos. Outros, como Wolkmer (2003, p. 1-30), preferem tratar do fenômeno de aquisição de direitos a partir do termo dimensão, pois entendem que a emergência de novos direitos não se concretiza com base no ocaso de outros. Os direitos fundamentais de primeira geração ou dimensão dizem respeito aos direitos individuais básicos. Com base na taxionomia proposta por Thomas Marshall, Zolo (2006, p. 41-42) distingue os direitos civis dos políticos. Para o autor, os direitos civis compreendem o direito à vida, a liberdade pessoal, a liberdade de palavra, pensamento e religião, a inviolabilidade do domićlio, a confidencialidade das comunicações pessoais, os direitos patrimoniais - propriedade, liberdade de iniciativa econômica, a autonomia de negociação -, o direito aos serviços do sistema judiciário e as garantias processuais como o habeas corpus, a serem utilizadas em face aos poderes repressivos do Estado. Já os direitos políticos afirmam "[...] o interesse dos cidadãos de participar do exercício do poder político como membros de órgãos investidos de autoridade decisória ou como eleitores de 
Direito.

Enquanto o Estado de Direito e o Estado de Direito Social eram pautados pelas lógicas do "Eu-contra-o-Estado" e do "Nóscontra-o-Estado", respectivamente, o Estado de Direito Ambiental encontra seu fundamento na fórmula "Nós-todos-em-favor-doPlaneta". 29

Tendo que conciliar uma gama de direitos fundamentais de diversas dimensões, muitos dos quais com características ou aspectos que parecem ser, à primeira vista, antagônicos, o primeiro obstáculo a ser enfrentado para a efetivação do Estado de Direito Ambiental reside na identificação de mecanismos inovadores, necessariamente abertos, que levem em consideração os diversos interesses em pauta, e que, a partir de critérios de preponderância, consigam fazer convergir as pretensões para soluções equilibradas, do ponto de vista ecológico, justas, do ponto de vista social e viáveis, do ponto de vista econômico.

A legislação brasileira encontrou um meio de equacionar este paradoxo criando e categorizando, por meio do artigo $81 \mathrm{da}$ lei federal n. ${ }^{\circ}$ 8078/1990 (Código de Defesa do Consumidor), os

tais órgãos.” (ZOLO, 2006, p. 42). Os direitos fundamentais de segunda geração ou dimensão decorrem da Revolução Industrial entre os séculos XIX e XX e buscam, através de movimentos sociais, estabelecerem melhorias na esfera social do homem trabalhador. Tais direitos conquistaram espaço e proteção após a Constituição alemã de Weimar e o Tratado de Versales (criação da OIT - Organização Internacional do Trabalho), diplomas que defendem os direitos sociais, culturais e econômicos da comunidade, com mediata aplicabilidade. Representam o valor da igualdade. Os direitos fundamentais de terceira geração ou dimensão são oriundos das mudanças ocorridas na geopolítica das últimas décadas do século passado e se direcionam à preservação da qualidade de vida. Segundo $\operatorname{Wolkmer}(2003$, p. 9): "São os direitos metaindividuais, direitos coletivos e difusos, direitos de solidariedade. A nota caracterizadora desses "novos" direitos é a de que seu titular não é mais o homem individual (tampouco regulam as relações entre os indivíduos e o Estado), mas agora dizem respeito à proteção de categorias ou grupos de pessoas (família, povo, nação), não se enquadrando nem no público, nem no privado." Os direitos de terceira geração ou dimensão são representados pelos direitos de fraternidade a exigir colaboração solidária de todos os seres humanos a nível global, ou seja, dos Estados e da coletividade. Esse direito emana prestações positivas e negativas de seus titulares. E vale salientar que a titularidade individual de um direito subjetivo ao meio ambiente não traz consigo a insubordinação do ambiente como bem jurídico coletivo. (BENJAMIN, 2007, p. 103)

29 BENJAMIN, 2007. 
direitos meta ou transindividuais, que são divididos, para fins de defesa coletiva dos direito e deveres de seus titulares em difusos, coletivos e individuais homogêneos, que se distinguem pelo grau de indivisibilidade dos direitos e interesses e pelo nível de indeterminação dos titulares de tais direitos e interesses.

O Código de Defesa do Consumidor alterou a Lei da Ação Civil Pública (Lei $\mathrm{n}^{\circ} 7347 / 1985$ ), incorporando à defesa de todo e qualquer direito e interesse difusos coletivo e individual homogêneo, os dispositivos nele previstos para a defesa dos interesses e direitos dos consumidores e das vítimas das relações de consumo.

No campo doutrinário, o direito brasileiro articulou um conceito de meio ambiente adequado ao caráter diacrônico do direito ao equilíbrio ecológico.

A partir das consagradas definições de meio ambiente que consideravam seus aspectos natural, artificial e cultural, autores como José Rubens Morato Leite, ${ }^{30}$ com o intuito de ultrapassar a dicotomia difuso/individual, conceituam o meio ambiente a partir de dois critérios, considerando-o como macro e microbem.

Enquanto macrobem, o meio ambiente é unitário, integrado, incorpóreo e imaterial, constituindo-se em bem de uso comum do povo, de interesse público e que pode ser defendido de forma autônoma, pela importância que representa para a qualidade de vida das atuais e futuras gerações. ${ }^{31}$

É, ainda, um direito fundamental do homem que reclama, para sua consecução, da participação e responsabilidade compartilhada do Estado e da Coletividade.

A configuração do meio ambiente como macrobem não afeta as características dos microbens que o integram.

O microbem ambiental é formado pelos elementos naturais, artificiais e culturais que, não obstante contribuírem para a manutenção do equilíbrio ambiental - tomado como macrobem, são passíveis de apropriação e utilização pelas atuais gerações para suas atividades socioeconômicas. ${ }^{32}$

30 Leite, 2000.

31 LEITE, 2000, p. 65.

32 LEITE, 2000, p. 65. 
A cisão entre macro e microbem ambiental importa na consideração da qualidade ambiental em um duplo grau de aplicabilidade: i) a primeira relacionada às condições de sanidade ambiental que permite a vida no planeta (macrobem) e; ii) a segunda relacionada à necessidade de serem mantidos os componentes desse bem maior, ou sejam os microbens.

A principal consequência da dupla definição do meio ambiente reflete-se no campo dos direitos correlatos.

A manutenção do equilíbrio ecológico constitui-se dever do Estado e de todos. No campo dos direitos, tem-se que danos ao equilíbrio ecológico importam na violação autônoma de direitos de dimensões distintas (difusa, coletiva e individual homogênea) a serem defendidas, de forma autônoma por todos e pelo Estado.

Neste ponto reside o principal desafio de um modelo de Estado que se propõe como de Direito Ambiental. Explica-se:

A elevação do meio ambiente a status de direito fundamental reflete significativamente no campo da hermenêutica constitucional ambiental. Por ser um direito fundamental, a garantia do meio ambiente saudável vincula o Estado à sua defesa e preservação dever positivo, representado por verdadeiras obrigações de fazer -, impondo-lhe restrições à atuação como agente empreendedor dever negativo, representado por obrigações de não fazer.

Esses deveres dependem de mecanismos ecologizados de comunicação e governança, que levem em consideração a interação entre o Estado e todos que compõem as atuais gerações e a interdependência dos direitos destes com os que precisam ser resguardados para as futuras gerações.

Ocorre que, todos os integrantes das atuais gerações não podem ser medidos a partir de critérios de territorialidade. Neste ponto, se ingressa no segundo desafio posto ao Estado de Direito Ambiental.

Se tal desafio já se mostra extremamente árduo de ser superado por um Estado territorialmente delimitado, sobre o qual exerce soberanamente sua força normativa, a dificuldade adquire proporções bem maiores quando se tratam de problemas e interesses que ultrapassam as fronteiras dos Estados. 


\subsection{DESAFIOS LIGADOS À PERDA DE CENTRALIDADE E DO PODER NORMATIVO DO ESTADO: O ESTADO DE DIREITO AMBIENTAL E OS PROCESSOS DE GLOBALIZAÇÃO}

A Declaração Mundial sobre o Estado de Direito Ambiental prevê diversos mecanismos para a implementação do Estado de direito ambiental. Dentre os quais, destacam-se: i) Sistemas de monitoramento e de informação que permitam uma avaliação precisa do estado do ambiente e das pressões sobre o mesmo; ii) medidas anticorrupção; iii) sistemas de gestão ambiental devidamente fundamentados, dando devida consideração ao risco ambiental e à vulnerabilidade dos sistemas sociais e econômicos, diante da deterioração ecológica; iv) avaliação ambiental multidimensional e policêntrica, que considere a complexidade das relações sócio ecológicas; v) ferramentas de modelagem quantitativas e qualitativas, que possibilitem o planejamento com base em estratégias resilientes; vi) sistemas de gestão e governança colaborativas, que envolvam interessados de diversas origens socioeconomicas e culturais, bem como grupos tradicionalmente marginalizados, incluindo os povos locais e indígenas, as mulheres e os pobres; vii) mecanismos de coordenação, como redes regionais de fiscalização, inteligência compartilhada e cooperação judiciária; viii) educação jurídica ambiental e capacitação de todas as pessoas, especialmente das mulheres, das meninas, dos líderes tradicionais e das autoridades indígenas, com foco no intercâmbio de conhecimentos sobre as melhores práticas, levando em conta os aspectos jurídicos, políticos, socioeconômicos, culturais, e religiosos, bem como o reconhecimento de características comuns baseadas em normas e padrões internacionais; ix) aproveitamento de novas tecnologias e meios de comunicação para promover a educação em direito ambiental e o acesso à informação; $x$ ) fortalecimento da sociedade civil, associações de direito ambiental e outros atores não estatais que preencham lacunas nos sistemas de governança ambiental de base estatal; xi) vinculação de crimes ambientais a outros crimes, tais como lavagem de dinheiro; xii) resolução de litígios de interesse público sobre a conservação e proteção do ambiente com base nos 
direitos das futuras gerações e xiii) fortalecimento da capacidade dos tribunais para atuar como garantes do Estado de direito ambiental. ${ }^{33}$

Os mecanismos e medidas acima indicam um forte compromisso com as questões sociais, já que não há como desvincular a qualidade do meio ambiente do bem-estar social. Ambos aspectos são faces de uma mesma moeda.

Há que se considerar, ainda, o aspecto econômico, pois o arrefecimento econômico leva ao empobrecimento e este, por sua vez, ao aumento da pressão sobre os recursos naturais, a não ser que os padrões atuais de qualidade de vida fossem alterados, o que não parece crível a médio e longo prazo.

Inexoravelmente, repousa o Estado de Direito Ambiental sobre a lógica do desenvolvimento sustentável, que determina um equilíbrio entre os elementos ecológicos, sociais e econômicos.

Mesmo que considerado sob a ótica da sustentabilidade forte, que apregoa maior relevância ao aspecto ecológico do desenvolvimento sustentável por ser a base sobre a qual se elevam os pilares da sociedade e da economia ${ }^{34}$ o modelo sustentável de desenvolvimento não pode prescindir dos demais elementos, por serem de vital importância para a vida humana.

Tem-se, dessa forma, o atrelamento do Estado de Direito Ambiental às diretrizes informadoras do desenvolvimento sustentável, o que, de certa forma, impede-o de implementar proposta mais radicais como a do decrescimento econômico.

Por outro lado, o Estado de Direito Ambiental continua - e continuará - a ser um Estado, gozando das mesmas prerrogativas e sofrendo das mesmas vicissitudes que acometem os Estados na atualidade.

Nesse sentido, interessante confrontar a proposta do Estado de Direito Ambiental, considerando a sua inserção num mundo que globalizou a economia e os riscos.

A partir da década de 1960, muitas das formas de organização político-sociais começam a entrar em colapso e o capitalismo dirigido começa a ser substituído pelo financeiro.

\footnotetext{
33 IUCN, 2016.

34 WINTER, 2009.
} 
No campo econômico, as consequências mais dramáticas da aplicação do ideário neoliberal são as seguintes: i) crescimento explosivo do mercado mundial, através da atuação das empresas multinacionais, ii) diminuição da capacidade reguladora dos Estados sobre a economia; iii) enfraquecimento dos mecanismos nacionais de regulação dos conflitos entre capital e trabalho; iv) precarização das condições de trabalho e do nível salarial; v) aumento da industrialização dependente dos países do terceiro mundo em função da flexibilização, automação dos processos fabris e melhorias nas condições de transporte e telecomunicações; vi) emergência de processos de desindustrialização e subcontratação; vii) crescente diferenciação dos produtos de consumo, possibilitando a particularização dos gostos; e viii) possibilidade de reprodução do capital em decorrência da mercadorização e da digitalização da comunicação. ${ }^{35}$

Essas tendências se agudizaram durante as três últimas décadas do século XX e nos primeiros anos do presente milênio, em um processo que globalizou não somente a economia, mas, também, o risco, criando o que Beck $^{36}$ denomina de sociedade de risco global, na qual os perigos produzidos pela civilização não podem ser delimitados socialmente, nem no espaço e nem no tempo. ${ }^{37} 38$

35 SANTOS, 2003, p. 87.

36 Beck, 2006, p. 29.

37 BECK, 2006, p. 29.

38 A sociedade de risco global apresenta as seguintes características: i) inter-relação entre dois conflitos, duas lógicas de distribuição: a distribuição de bens e males - enquanto que na sociedade industrial os embates se travavam em torno da distribuição das riquezas advindas da produção de bens, na sociedade global do risco, procura-se equacionar os efeitos globais, dentre os quais os impingidos ao meio ambiente, da radicalização da produção industrial, baseada na globalização do capital; ii) debilitação dos fundamentos do cálculo do risco, haja vista a impossibilidade de serem compensados financeiramente danos decorrentes do agravamento do nível de desemprego, do subemprego e da pobreza; iii) debilitação das burocracias e do domínio da economia clássica e redefinição das fronteiras e frentes de batalha da política contemporânea em face do desencadeamento de uma dinâmica de mudanças culturais e políticas em função da explosividade social dos riscos financeiros globais; iv) colapso da instituição Estado-nação; v) emergência do conceito de globalização responsável como tema público e político de alcance mundial em virtude da reflexibilidade causada pelo risco; e vii) surgimento de novas opções: protecionismo 
A ascensão da sociedade de risco global deve ser entendida dentro de um contexto mais amplo, de uma sociedade complexa, onde atuam atores específicos em conflito constante com o objetivo de estabelecerem um "[...] monopólio sobre o tipo de capital que aí se faz efetivo - a autoridade cultural no campo artístico, a autoridade científica no campo científico, a autoridade sacerdotal no campo religioso e assim sucessivamente". ${ }^{39}$

Tal campo social, na atualidade, corresponde ao mundo globalizado.

As alterações provocadas pela globalização introduziram uma nova racionalidade na estrutura geopolítica mundial, constituindo-se num vasto e intenso campo de conflitos entre grupos sociais, Estados e interesses hegemônicos, por um lado; e grupos sociais, Estados e interesses subalternos, por outro. ${ }^{40}$

Como processo hegemônico, a globalização é fruto de um consenso estabelecido entre as grandes potências econômicas mundiais, o Consenso de Washington, o qual, de acordo com Santos, ${ }^{41}$ encontra-se estruturado a partir de três consensos subjacentes:

i) O consenso do Estado Fraco, em cuja base se encontra a ideia de que a economia neoliberal necessita de uma sociedade civil forte. Para tanto, é necessário diminuir o tamanho e o poderio do Estado. Ocorre que, para que haja o encolhimento do Estado, é necessária uma intensa atividade regulatória do Estado, o que, por si só, implica um paradoxo; ii) o consenso da democracia liberal, que visa dar forma política homogênea ao Estado fraco, se descurando, todavia, do fato de ter de ser aplicada à realidades distintas, convertendo-se em uma versão caricatural de democracia liberal; iii) o consenso sobre o primado do direito e do sistema judicial que requer um novo arranjo legal, adequado à liberação

nacional e regional, instituições transnacionais e democratização. (BECK, 2006, p. 12)

39 BOURDIEU; WACQUANT apud AZUELA, 2005, p. 107.

40 SANTOS, 2005.

41 Santos, 2005, p. 41-44. 
dos mercados, investimentos e sistema financeiro, fazendo emergir um conjunto de instituições independentes e universais para criar expectativas e resolver litígios.

Os problemas que o processo de globalização vem causando são globais, imensos e muito bem documentados. Quantidades maciças de capital fluem ao redor do mundo, mas a maior parte desse fluxo se concentra nas regiões industrializadas e em escassos mercados na América Latina e na Ásia. Ele mal atinge as áreas mais pobres, que precisam desesperadamente de investimento em capital. As desigualdades econômicas mundiais são muito grandes. Cerca de quatrocentos dentre os indivíduos mais ricos do mundo têm mais bens do que os três bilhões mais pobres em conjunto. Os níveis de poluição global continuam crescendo, e o farão ainda que as metas de Quioto sejam atingidas, o que parece improvável. A violência fundamentalista irrompeu em muitas partes do mundo, e parece propensa a se tornar ainda mais comum. ${ }^{42}$

Jacobs $^{43}$ indica como principais efeitos da globalização os seguintes fenômenos: i) a integração da economia mundial, com a liberação do comércio que oportuniza maior volatilidade nos fluxos de capital, expondo, assim, os mercados nacionais e de exportações a pressões competitivas mais severas. Além disso, se verifica uma forte integração entre processos de produção de bens e serviços e conhecimento, ocasionando a ascensão da economia do conhecimento; ii) no campo social, a exacerbação de processos de destradicionalização fazendo com que as pessoas se desvinculem do "[...] poder declinante das autoridades, costumes e sistemas de crença tradicionais [...]" e se tornem indivíduos "[...] reflexivos, sendo obrigados a fazer escolhas ativas e a repensar suas respostas em cada nova circunstância que enfrentam, pouco dispostos a recorrer à tradição e ao hábito e incapazes de fazê-lo mesmo que o desejassem.”; iii) por fim, um dos principais efeitos da globalização é o aumento da desigualdade, pelo favorecimento advindo a determinadas regiões em decorrência da internacionalização de atividades econômicas, como acontece, por exemplo entre o

\footnotetext{
42 GIDDENS, 2007, p. 37-38.

43 Jacobs, 2007, p. 445-447.
} 
leste asiático e a África e pelo aumento da oferta de mão-de-obra na base do mercado de trabalho, o que mantém os salários das categorias menos especializadas em baixa, “[...] enquanto no topo recompensas vultosas se oferecem àqueles com habilidades escassas e comerciáveis".

Muito embora a relevância de serem tratados adequadamente os grandes efeitos globais ocasionados pelo processo de globalização, acima descritos, e de se ter a noção de que o tratamento adequado de tais problemas passa, necessariamente, pelo estudo conjunto destes em uma perspectiva, no mínimo, multidisciplinar, no presente trabalho, por limitações de tempo e espaço, propõe-se restringir a análise à inaptidão do Estado para enfrentar os riscos impostos pelo fenômeno.

Realizando uma classificação dos riscos mundiais, Beck ${ }^{44}$ distingue três espécies de ameaças globais. No primeiro grupo estão incluídas a destruição ecológica e os perigos tecnológicos-industriais motivados pela riqueza, ou seja, os perigos a que a humanidade e o planeta encontram-se expostos pelo acúmulo de externalidades negativas ocasionadas em função da necessidade de serem mantidos os padrões de vida alcançados até a presente época, tais como o buraco na camada de ozônio, o efeito estufa, a escassez de água em determinadas regiões e os riscos imprevisíveis da manipulação genética de plantas e seres humanos.

Em um segundo grupo, encontram-se os riscos relacionados com a modernização incompleta, com a pobreza, como, por exemplo, as taxas de desmatamentos em florestas tropicais e os resíduos tóxicos muitas vezes importados de outros países e os oriundos da aplicação de tecnologias obsoletas em processos fabris. Segundo Zürn ${ }^{45}$ : “[...] a destruição ambiental causada pela riqueza se distribui igualmente em todo o mundo, enquanto que as destruições ambientais causadas pela pobreza são locais e somente se internacionalizam em forma de efeitos colaterais a um prazo médio".

O terceiro grupo é formado pelas ameaças procedentes das

44 Beck, 2006, p. 54-58.

45 Zürn apud BECK 2006, 55. 
armas de destruição maciça (armas nucleares, biológicas e químicas), as quais, não obstante o término do conflito leste oeste, continuam presentes e encontram-se agravadas em função do fundamentalismo religioso e do terrorismo privado, que vêm somar-se à possibilidade de conflitos militares entre Estados.

Ponto comum a unir os três grupos acima é o fato de serem globais e complexos.

Por terem sido geradas ou agravadas pelo processo de globalização, as ameaças apontadas por Beck $^{46}$ não se apresentam passíveis de serem solucionadas, minimizadas e controladas por Estados geograficamente localizados. Estes dependem, para tanto, de instituições supranacionais e acordos bilaterais que demandam a participação e o efetivo envolvimento de um grande número de Nações, sendo, por isso, globais em um duplo sentido, tanto em relação aos seus efeitos, como à maneira ou forma de serem solucionadas ou controladas.

Além de serem intrinsecamente globais, as ameaças apresentadas por Beck ${ }^{47}$ são fruto e, ao mesmo tempo, influenciam sociedades e realidades extremamente complexas nas quais o sistema político - pautado na racionalidade moderna - há muito perdeu a sua efetividade e vem sendo mitigado por uma crescente emergência de subsistemas, ou campos subpolíticos, que, da mesma forma, põem em cheque o poder normativo do Estado moderno.

Rocha e Carvalho ${ }^{48}$ asseveram: "O Estado nacional foi considerado durante muito tempo como a organização mais importante da Política, comunicando-se com os demais sistemas, [...]. No final do século XX e início do XXI surgiram manifestações políticas transnacionais que abalaram os processos tradicionais de comunicação”.

A desterritorialização e a transnaciolização de setores importantes do sistema social retiraram o Estado da centralidade deste sistema. A perda de referência decorreu da natureza

\footnotetext{
46 Beck, 2006.

47 Beck, 2006.

48 ROCHA; CARVALHO, 2006, p. 11.
} 
policontextual ${ }^{49}$ da sociedade mundial, na qual gravitam atores tão ou mais poderosos que os Estados, com interesses muitas vezes colidentes com os destes.

Conforme Teubner, ${ }^{50}$ a globalização fez com que os processos de diferenciação fossem quantitativa e complexamente incrementados ocasionando um "[...] deslocamento de proeminência no princípio primário da diferenciação diretriz: um deslocamento da diferenciação territorial para a funcional em nível mundial [...]”, possibilitando a "[...] autonomização de processos comunicativos em dimensão global, com a fragmentação da sociedade em dimensões comunicativas altamente dinâmicas, complexas e que, como condição de sua operacionalidade, envolvem conhecimentos e tecnologias altamente desenvolvidas e específicas. "A partir dessa perspectiva, pode ser observado que os Estados-nação não representam as sociedades por si próprios, como tradicionalmente $\mathrm{o}$ faziam através de uma centralidade do político, pois encontram-se fundados numa diferenciação funcional.”. ${ }^{51}$

Como consequência, experimenta-se atualmente um descompasso entre a natureza de diversos sistemas, cada vez mais complexos, globais, seletivos e independentes e o poder normativo do Estado, por se encontrar centrado em uma racionalidade orientada pelos princípios da territorialidade, soberania, autonomia e legalidade, ${ }^{52}$ ocasionando, assim, a perda da centralidade tradicional do Estado como unidade privilegiada de iniciativa econômica, social e política. ${ }^{53}$

Como a implementação dos mecanismos previstos na Declaração Mundial sobre o Estado de Direito Ambiental dependem, em grande parte, do protagonismo do Estado, é preciso lhe devolver

49 "A policontextularidade é uma metáfora reutilizada como critério de investigação da fragmentação do sentido da pós-modernidade, sendo uma interessante perspectiva para a análise do Pluralismo Jurídico Transnacional”. (ROCHA; CARVALHO, 2006, p. 10).

50 Teubner, 2003, p. 22.

51 ROCHA; CARVALHO, 2006, p. 16.

52 VIEIRA, 2001, p. 27.

53 SANTOS, 2005, p. 36. 
o protagonismo que perdeu frente à globalização - o que parece ser uma tarefa hercúlea - ou arquitetar mecanismos de governança global pautados na ação conjunta do Estado com novos atores sociais que vêm, gradativamente, assumindo seus espaços no campo social globalizado.

\section{CONCLUSÃO}

O presente artigo analisou dois dos desafios para a concretização da proposta de Estado de Direito Ambiental.

Os limites e as possibilidades para a efetivação desse modelo de Estado foram problematizados a partir das contradições de um dos seus princípios fundantes: o direito fundamental ao meio ambiente e da perda de poder normativo do Estado diante de um cenário policontextural representado pela globalização.

Muito embora classificado como direito de terceira geração ou dimensão, que tem na solidariedade a sua característica fundante, o direito fundamental ao meio ambiente apresenta traços dos direitos individuais de primeira geração ou dimensão, gestados sobre a contraposição entre sujeito e Estado, que deve se abster de atingir esferas de garantias que compõem o núcleo central de proteção dos indivíduos.

A difusidade do direito ao meio ambiente não permite que ele seja usufruído individualmente pelos seus titulares, quando e se individualmente considerados. Ou a qualidade do meio ambiente é gozada por todos os integrantes das presentes gerações ou ela não é usufruída por ninguém.

O direito ao meio ambiente ecologicamente equilibrado é marcado, ainda, pela diacronia, ou seja, é um direito que, ao mesmo tempo pertence às atuais e às futuras gerações, transformando os titulares atuais em fiduciários de um direito a ser utilizado por futuros fiduciários, posto que, por força da solidariedade intergeracional, as futuras gerações terão a mesma incumbência de manter as qualidades ambientais necessárias para a vida das gerações que as sucederão.

Esta redução do conteúdo material do direito ao meio ambiente ecologicamente equilibrado, que transforma seus titulares em fiduciários, com poderes para utilizar com parcimônia os 
recursos naturais e deveres para com a preservação de uma base ecológica segura não se coaduna com as fórmulas que marcam as gerações ou dimensões anteriores e se constitui no primeiro desafio a ser superado para a efetivação do Estado de Direito Ambiental.

A ecologização do Estado se apresenta como o grande desafio para a retomada de seu protagonismo e poder normativo, no atual estágio da globalização econômica.

A promoção do bem-estar ambiental na sua base territorial, desiderato básico do Estado de Direito Ambiental, impõe a sua reorientação no âmbito externo.

Em outros termos, os problemas ambientais globais devem ser tratados como tais, a partir de sistemas de monitoramento e de informações ambientais globais, avaliações ambientais que levem em consideração a biosfera e as relações sócio ecológicas de todas as comunidades terrestres, sistemas de governança colaborativos, que envolvam interessados de diversas origens socioeconomicas e culturais, mecanismos de coordenação e cooperação globais; fortalecimento de entidades civis cosmopolitas que defendam o patrimônio comum da humanidade e criação e fortalecimento de tribunais ambientais mundiais, que atuarão como garantidores do meio ambiente.

Estes instrumentos, que integram a Declaração Mundial sobre o Estado de Direito Ambiental, hão que ser estrategicamente pensados para a atuação a nível global.

\section{REFERÊNCIAS}

ART, Henry W. (Ed.). Dicionário de ecologia e ciência ambiental. Trad. Mary Amazonas Leite de Barros. São Paulo: Companhia Melhoramentos, 1998.

AZUELA, Antonio. Em torno dos fundamentos socioculturais do direito ambiental. In: FREITAS, Vladimir Passos de (coord.). Direito ambiental em evolução - n. 4. Curitiba: Juruá, 2005, p. 95-122.

BECK, Ulrich. La sociedad del riesgo global. $2^{a}$ ed. Trad. Jesús Alborés Rey. Madrid: Siglo XXI de Espana. 2006.

BELlO FILHO, Ney de Barros. Teoria do direito e ecologia: apontamentos para um direito ambiental no século XXI. In: FERREIRA, 
Helini Sivini; LEITE, José Rubens Morato (orgs.). Estado de Direito Ambiental: tendências: aspectos constitucionais e diagnósticos. Rio de Janeiro: Forense, 2004, p. 71-108.

BENJAMIN, Antônio Herman. Direito constitucional ambiental brasileiro. In: CANOTILHO, José Joaquim Gomes; LEITE, José Rubens Morato (orgs.). Direito constitucional ambiental brasileiro. Rio de Janeiro: Saraiva, 2007. p. 57-130.

BERTICELLI, Ireno Antônio. A origem normativa da prática educacional na linguagem. Ijuí: Editora Unijuí, 2004.

BOBBIO, Norberto. A era dos direitos. Rio de Janeiro: Campus, 1992.

CANOTILHO, José Joaquim Gomes. Estado constitucional ecológico e democracia sustentada. In: FERREIRA, Helini Sivini; LEITE, José Rubens Morato (orgs.). Estado de Direito Ambiental: tendências: aspectos constitucionais e diagnósticos. Rio de Janeiro: Forense, 2004, p. 3-16.

CAPRA, Fritjof. Alfabetização ecológica: o desafio para a educação do século XXI. In: TRIGUEIRO, André (coord.). Meio ambiente no século 21: 21 especialistas falam da questão ambiental nas suas áreas de conhecimento. Rio de Janeiro: Sextante, 2003, p. 19-33.

COSTA, Pietro. O Estado de Direito: uma introdução histórica. In: ; Zolo, Danilo (orgs.). O Estado de Direito: história, teoria, crítica. São Paulo: Martins Fontes, 2006, p. 95-198.

DERANI, Cristiane. Direito ambiental econômico. São Paulo: Max Limonad, 1997.

DUARTE, Marise Costa de Souza. As novas exigências do direito ambiental. In: LEITE, José Rubens Morato; BELLO FILHO, Ney de Barros (orgs.). Direito ambiental contemporâneo. Barueri: Manole, 2004, p. 503-530.

GIDDENS, Antony. Introdução. In: GIDDENS, Antony (org.). O debate global sobre a Terceira via. Trad. Roger Maioli dos Santos. São Paulo: Editora Unesp, 2007, p. 17-43.

IUCN. World Declaration on the Environmental Rule of Law. Disponível em: <http://iucnael2016.no/wp-content/uploads/2016/06/WORLDDECLARATION-ON-THE-ENVIRONMENTAL-RULE-OF-LAW- 
Near-Final-Draft-.pdf>. Acesso: dez 2016.

JACOBS, Michael. O meio ambiente, a modernidade e a terceira via. In: GIDDENS, Antony (org.). O debate global sobre a terceira via. Trad. Roger Maioli dos Santos. São Paulo: Editora Unesp, 2007, p. 443-472.

KLOEPFER, Michael. A caminho do Estado Ambiental? Trad. Carlos Alberto Molinaro. Disponível em: <https://www.google. com.br/webhp? sourceid =chrome-instant $\&$ rlz $=1$ C 1 CHZL_pt BRBR709BR709\&ion=1\&espv=2\&ie=UTF-8\#q=estado + de + direito + ambiental+kloepfer\&* $>$. Acesso: dez 2016.

LEFF, Enrique. Saber ambiental: sustentabilidade, racionalidade, complexidade, poder. $3^{a}$ ed. Trad. Lúcia Mathilde Endlich Orth. Petrópolis: Vozes, 2001.

LEITE, José Rubens Morato. Dano Ambiental: do individual ao coletivo extrapatrimonial. São Paulo: Editora Revista dos Tribunais, 2000.

. Sociedade de risco e Estado. In: CANOTILHO, José Joaquim Gomes; LEITE, José Rubens Morato (orgs.). Direito constitucional ambiental brasileiro. Rio de Janeiro: Saraiva, 2007. p. 130-204.

LEITE, José Rubens Morato; AYALA, Patryck de Araújo. Novas tendências e possibilidades do direito ambiental no Brasil. In: WOLKMER, Antônio Carlos; LEITE, José Rubens Morato (orgs.). Os novos direitos no Brasil: natureza e perspectivas. São Paulo: Saraiva, 2003, p. 181-292.

MACHADO, Paulo Afonso Leme. Direito ambiental brasileiro. $10^{\mathrm{a}} \mathrm{ed}$. Rev., atual. e ampli. São Paulo: Malheiros, 2002.

MARSHALL, Thomas Humphrey. Cidadania, classe social e status. Rio de Janeiro: Zahar, 1967.

MILARÉ, Édis. Direito do ambiente: doutrina, prática, jurisprudência, glossário. $4^{a}$ ed. Rev., atual. e ampli. São Paulo: Revista dos Tribunais, 2005.

OST, François. A natureza à margem da lei: a ecologia à prova do direito. Lisboa: Instituto Piaget, 1997.

ROCHA, Leonel Severo; CARVALHO, Delton Winter de. Policontextularidade e direito ambiental reflexivo. In: Revista Seqüência: 
estudos jurídicos e políticos $-\mathrm{n}^{\circ}$ 53. Florianópolis: Fundação Boiteux, 2006, p. 9-28.

ROMEIRO, Ademar Ribeiro. Economia ou economia política da sustentabilidade. In: MAY, Peter H.; LUSTOSA, Maria Cecília; VINHA, Valéria da (orgs). Economia do meio ambiente: teoria e prática. Rio de Janeiro: Elsevier: 2003, p. 1-29.

SANTOS, Boaventura de Sousa. Pela mão de Alice: o social e o político na pós-modernidade. 9. ed. São Paulo: Cortez, 2003.

- Os processos da globalização. In: SANTOS, Boaventura de Sousa (org.). A globalização e as ciências sociais. $3^{a}$ ed. São Paulo: Cortez, 2005, p. 25-102.

TEUBNER, Gunther. Global Bukowina: Legal Pluralism in the World Society. In: Gunther Teubner (ed.). Global law without state. Great Britain: Datmouth Publishing Company Limited, 2003.

WINTER, Gerd. Desenvolvimento sustentável, OGM e responsabilidade civil na União Europeia. Campinas: Millennium Editora, 2009.

WOLKMER, Antônio Carlos; LEITE, José Rubens Morato (orgs.). Os novos direitos no Brasil: natureza e perspectivas. São Paulo: Saraiva, 2003.

ZOLO, Danilo. Teoria e crítica do Estado de Direito. In: COSTA, Pietro; Zolo, Danilo (orgs.). O Estado de Direito: história, teoria, crítica. São Paulo: Martins Fontes, 2006, p. 3-94.

Recebido em: 21/09/2017

Aprovado em: 12/12/2017 